\title{
Once-Daily Oral Semaglutide Versus Injectable GLP-1 RAs in People with Type 2 Diabetes Inadequately Controlled on Basal Insulin: Systematic Review and Network Meta-analysis
}

\author{
Barrie Chubb (D) · Palvi Gupta · Jatin Gupta · Solomon Nuhoho • \\ Klaus Kallenbach · Michelle Orme
}

Received: December 22, 2020 / Accepted: February 13, 2021 / Published online: March 16, 2021

(C) The Author(s) 2021

\section{ABSTRACT}

Introduction: The relative efficacy and safety of once-daily oral semaglutide vs. injectable glucagon-like peptide-1 receptor agonists (GLP-1 RAs) in subjects with type 2 diabetes (T2D) inadequately controlled on basal insulin were assessed using network metaanalysis (NMA).

Methods: A systematic literature review (SLR) was performed to identify randomised controlled trials of GLP-1 RAs in this population. Data at $26 \pm 4$ weeks were extracted for efficacy

Supplementary Information The online version contains supplementary material available at https:// doi.org/10.1007/s13300-021-01034-w.

B. Chubb $(\square)$

Novo Nordisk Ltd, Gatwick, UK

e-mail: bach@novonordisk.com

P. Gupta

DRG Abacus Part of Clarivate, Bangalore, India

J. Gupta

DRG Abacus Part of Clarivate, Gurgaon, India

S. Nuhoho $\cdot$ K. Kallenbach

Novo Nordisk A/S, Søborg, Denmark

M. Orme

ICERA Consulting, UK on behalf of DRG Abacus Part of Clarivate, Swindon, UK and safety outcomes feasible for the NMA: change from baseline in glycated haemoglobin $\left(\mathrm{HbA}_{1 \mathrm{c}}\right)$, weight and blood pressure; $\mathrm{HbA}_{1 \mathrm{c}}$ target levels $(<7.0 \%$ and $\leq 6.5 \%)$; composite endpoint; incidence of nausea, vomiting or diarrhoea. Comparators of interest were all licensed doses of dulaglutide, exenatide, liraglutide, lixisenatide and once-weekly injectable semaglutide.

Results: The NMA included seven trials. Oncedaily oral semaglutide $14 \mathrm{mg}$ was associated with significantly greater $\mathrm{HbA}_{1 \mathrm{c}}$ reductions vs. most comparators (treatment differences: -0.42 to $-1.32 \%)$; differences vs. onceweekly injectable semaglutide $(0.5 \mathrm{mg}$ and $1 \mathrm{mg}$ doses) were not statistically significant. Oncedaily oral semaglutide $14 \mathrm{mg}$ was associated with significantly greater weight reductions vs. exenatide $2 \mathrm{mg}$ and lixisenatide $20 \mu \mathrm{g}(-2.21$ and $-2.39 \mathrm{~kg}$ respectively); non-statistically significant weight reductions in favour of oncedaily oral semaglutide $14 \mathrm{mg}$ were observed vs. all other comparators except once-weekly injectable semaglutide $1 \mathrm{mg}$. Similar trends were observed for the proportion of subjects achieving $\mathrm{HbA}_{1 \mathrm{c}}<7.0 \%$ and $\leq 6.5 \%$ and the composite endpoint. Once-daily oral semaglutide $14 \mathrm{mg}$ was associated with similar odds of experiencing nausea, vomiting or diarrhoea vs. all comparators.

Conclusion: Once-daily oral semaglutide $14 \mathrm{mg}$, as an add-on to basal insulin, is an efficacious treatment for reducing $\mathrm{HbA}_{1 \mathrm{c}}$ and 
weight and meeting glycaemic targets at $26 \pm 4$ weeks. Once-daily oral semaglutide $14 \mathrm{mg}$ also offers the option of an oral treatment with similar or better efficacy and similar tolerability vs. most injectable GLP-1 RAs.

Keywords: Basal insulin; GLP-1; Glycaemic control; Network meta-analysis; Semaglutide; Systematic review; Type 2 diabetes

\section{Key Summary Points}

Why carry out this study?

Currently, there are no head-to-head trials comparing once-daily oral semaglutide with injectable glucagon-like peptide-1 receptor agonists (GLP-1 RAs) as an addon to insulin therapy

Given the progressive nature of type 2 diabetes (T2D), comparative data in people with advanced disease are highly valuable to guide clinical decision-making for this population

This study sought to assess the relative efficacy and safety of once-daily oral semaglutide vs. injectable GLP-1 RAs in people with T2D inadequately controlled on basal insulin, using network metaanalysis

What was learned from the study?

Once-daily oral semaglutide $14 \mathrm{mg}$, as an add-on to basal insulin, is an efficacious treatment that offers people with T2D the option of an oral treatment with similar or better efficacy and similar tolerability compared with most injectable GLP-1 RAs

\section{DIGITAL FEATURES}

This article is published with digital features, including a summary slide, to facilitate understanding of the article. To view digital features for this article, go to https://doi.org/10.6084/ m9.figshare.13953326.

\section{INTRODUCTION}

Type 2 diabetes (T2D) is a chronic, progressive disease characterised by hyperglycaemia (i.e. elevated levels of blood glucose) and is associated with microvascular and macrovascular complications [1], which can reduce life expectancy, impair quality of life and increase treatment costs associated with diabetes [2-4].

Due to the progressive nature of $\mathrm{T} 2 \mathrm{D}$, treatment is often intensified over time to achieve adequate glycaemic control; the recommended target glycated haemoglobin $\left(\mathrm{HbA}_{1 \mathrm{c}}\right)$ levels for many people are either $<7.0 \%(53 \mathrm{mmol} / \mathrm{l})$ or $\leq 6.5 \%$ (48 mmol $/ \mathrm{mol}$ ) [5-9]. For those who do not meet their glycaemic targets after initial metformin treatment, current American Diabetes Association (ADA)/European Association for the Study of Diabetes (EASD) guidelines recommend intensifying treatment with sulfonylureas (SU), thiazolidinediones (TZD), dipeptidyl peptidase-4 inhibitors (DPP-4i), sodium-glucose co-transporter-2 inhibitors (SGLT-2is) or glucagon-like peptide 1 receptor agonists (GLP-1 RAs) [10].

Despite intensive non-insulin therapy, some people require insulin treatment, typically basal insulin, to achieve and maintain target $\mathrm{HbA}_{1 \mathrm{c}}$ levels $[7,10,11]$. However, a significant proportion of people receiving basal insulin across Europe $(78.1 \%)$ and the USA (72.2\%) still have inadequate glycaemic control at 3 and 24 months post-initiation, respectively [12]. Treatment can be further intensified by adding rapid-acting bolus insulin, other oral anti-diabetic drugs or injectable GLP-1 RA [7, 10, 11]. The combination treatment of GLP-1 RAs and basal insulin has demonstrated robust glycaemic control without an increase in hypoglycaemia or weight gain, compared with the addition of mealtime insulin [10, 13, 14].

Once-daily oral semaglutide is the first GLP-1 RA in a tablet formulation for the treatment of T2D in adults. The Peptide InnOvatioN for Early diabEtes tReatment (PIONEER) phase 3 clinical trial programme provided extensive 
evidence on the efficacy and safety of oncedaily oral semaglutide in a broad population with T2D, ranging from early to late disease stage [15-19]. The PIONEER 8 study demonstrated the efficacy of once-daily oral semaglutide as an add-on to insulin therapy in people with T2D who were uncontrolled on insulin (with or without metformin); once-daily oral semaglutide provided superior reductions in $\mathrm{HbA}_{1 \mathrm{c}}$ levels and body weight vs. placebo, enabling up to $54 \%$ of people with T2D to achieve $\mathrm{HbA}_{1 \mathrm{c}}<7.0 \%$ at 52 weeks [19]. Better glycaemic control was achieved with both doses of once-daily oral semaglutide (7 and $14 \mathrm{mg}$ ) vs. placebo at 26 and 52 weeks, despite lower total daily insulin dosages relative to baseline [19].

Several treatment options for T2D are currently available, thereby requiring that decision-makers understand the relative clinical benefits of each treatment to provide the best recommendations within budgetary constraints. Currently, there is no evidence from direct head-to-head trials between once-daily oral semaglutide and injectable GLP-1 RAs as an add-on to insulin therapy. Given the progressive nature of $\mathrm{T} 2 \mathrm{D}$, comparative evidence demonstrating the clinical benefits of oncedaily oral semaglutide in people with advanced T2D would be valuable to guide clinical decision-making for this population. Network metaanalysis (NMA) allows the use of all available trial data by combining direct and indirect evidence. Thus, the objective of this study was to conduct a systematic literature review (SLR) and an NMA to assess the relative efficacy and safety of GLP-1 RAs as an add-on to insulin therapy in people with T2D inadequately controlled on basal insulin.

\section{METHODS}

\section{Systematic Literature Review}

An SLR was performed, in accordance with the Centre for Reviews and Dissemination and the Cochrane Collaboration guidelines $[20,21]$, to identify randomised controlled trials on all currently used T2D pharmacotherapies and patient populations. Methodology and results presented herein are specific to studies reporting the efficacy and safety of once-daily oral semaglutide and injectable GLP-1 RAs in people with T2D inadequately controlled on basal insulin.

Study selection criteria were defined in terms of population, interventions, comparisons, outcomes and study design (PICOS) to ensure that potentially relevant studies were selected systematically to minimise bias $[20,21]$. The search strategy and PICOS criteria are reported in the supplementary material. Briefly, a database search of MEDLINE ${ }^{\circledR}$, EMBASE and the Cochrane Library (Tables S1-S4) was performed via the Ovid platform on 5 April 2016 and updated on 9 July 2019. Conference proceedings were searched including the EASD, the International Society for Pharmacoeconomics and Outcomes Research (ISPOR), the International Diabetes Federation and the ADA Scientific Sessions. Studies were screened independently by two reviewers against the PICOS selection criteria for inclusion in the SLR (Table S5). To provide a robust summary of relative treatment effects, an analysis was conducted to assess the degree of heterogeneity between the trials included in the network in terms of participants, study design, interventions and outcomes (full analysis available in supplementary material) [22]. A quality assessment of the trials was also conducted using the Cochrane Risk of Bias Assessment [21].

\section{Network Meta-analysis}

An NMA was performed, in accordance with guidance from the National Institute for Health and Care Excellence (NICE) and ISPOR Good Research Practise Task Force [23-26], to assess the relative efficacy and safety of once-daily oral semaglutide compared with injectable GLP-1 RAs for the treatment of T2D as an addon to insulin therapy. In the analysis, the primary intervention of interest was once-daily oral semaglutide (7 and $14 \mathrm{mg}$ doses). The primary comparators of interest were all licensed doses of injectable GLP-1 RAs approved for the treatment of T2D-once-weekly dulaglutide, twice-daily exenatide, once-weekly exenatide 
extended-release, once-daily liraglutide, oncedaily lixisenatide, and once-weekly injectable semaglutide. Albiglutide was included in the SLR but was subsequently excluded as it was withdrawn from the market in 2017 [27] and is no longer a relevant comparator.

The add-on to insulin population was defined as subjects with T2D inadequately controlled on insulin. To ensure the comparator trials chosen for inclusion in the NMA matched the index trial (i.e. PIONEER 8) in terms of population and background of insulin therapy, the definition was closely aligned with the population in PIONEER 8-people with T2D inadequately controlled on insulin (basal, basalbolus or premix regimens) with or without metformin. As there were very few trials that included the mixed insulin background, and 10 of the 12 trials included basal insulin as the background therapy, the base case was chosen based upon this population. Of note, the PIONEER 8 trial used two different estimands. The treatment policy estimand evaluated the treatment effect for all randomised subjects regardless of trial product discontinuation and use of rescue medication (data analysed using multiple imputation), whereas the trial product estimand evaluated the treatment effect for all randomised subjects under the assumption that they remained on the trial product for the entire planned duration of the trial and did not use rescue medication (data analysed using a mixed model for repeated measures) [28]. To allow for robust comparisons with trials reporting data without the use of rescue medication, the trial product estimand from PIONEER 8 was used for this NMA. The same statistical approach (i.e. mixed model for repeated measures) was used in the majority of the included comparator trials, which further supports the use of the trial product estimand from the PIONEER 8 trial.

A feasibility assessment was conducted to assess the quality of the studies and to ensure that study populations, treatments, outcomes and time points were aligned to provide robust analysis and clinically meaningful results. It was considered feasible to examine all trials identified in the SLR for data on at least one of the following efficacy outcomes: change from baseline in $\mathrm{HbA}_{1 \mathrm{c}}$, systolic blood pressure (SBP) and body weight; proportion of people with T2D achieving $\mathrm{HbA}_{1 \mathrm{c}}<7 \%$ or $\leq 6.5 \%$; and a composite endpoint defined as $\mathrm{HbA}_{1 \mathrm{c}}<7 \%$ without weight gain or hypoglycaemia. This composite endpoint was included in the analysis as it is increasingly used as a primary or secondary outcome in T2D trials to address the multiple goals recommended by current ADA guidelines $[10,29]$. The following safety outcomes were also assessed in the NMA: incidence of nausea, vomiting or diarrhoea. Feasibility was assessed at two time points: $26 \pm 4$ weeks and $52 \pm 4$ weeks; no analysis was feasible at $52 \pm 4$ weeks as only two studies $[30,31]$ reported data at these time points.

\section{Statistical Analysis}

Analyses of continuous outcomes (using a normal likelihood, identity link, shared parameter model) and dichotomous outcomes (using a binomial likelihood, logit link model) feasible for assessment were implemented in WinBUGS (MRC Biostatistics Unit, Cambridge, UK) [32] using a Bayesian approach involving the formal combination of a prior probability distribution and a likelihood distribution, and three Markov Monte-Carlo chains (10,000 iterations). The fixed-effects model was chosen for all the base case analyses. A random-effects analysis was not conducted as there were no pairs of treatments in the evidence network supported by more than one trial, which would result in poor estimates of the distribution of intervention effects [33]. Assessment of the convergence and autocorrelation was performed by analysing history and density plots, and Brooks-Gelman-Rubin diagnostic plots [33].

\section{Presentation of Results}

Results are presented as mean treatment differences or odds ratios (ORs) and an associated 95\% credible interval. For continuous outcomes of interest, $\mathrm{HbA}_{1 \mathrm{c}}, \mathrm{SBP}$ and body weight, a treatment is favoured if the mean difference is $<0$ vs. another treatment. For dichotomous efficacy outcomes, a treatment associated with an $O R \geq 1$ (e.g. higher odds for achieving 
$\mathrm{HbA}_{1 \mathrm{c}}<7 \%$ vs. another treatment) is favoured. For dichotomous safety outcomes, where reducing the probability of an adverse event is desirable, a treatment associated with an OR $<1$ is favoured. Once-daily oral semaglutide may achieve a numerical reduction/increase vs. a comparator, and if the $95 \%$ credible interval excludes the 0.0 (treatment differences) or 1.0 (ORs) the difference is defined as statistically significant. It should be noted that numerical difference is used in this NMA to indicate treatment differences that are not statistically significant. Additionally, the median ranks of each treatment and the surface under the cumulative ranking (SUCRA) are provided. The SUCRA is a numerical summary statistic of cumulative ranking probability plots (i.e. the probability a treatment is among the top $n$ treatments) [34]. A higher SUCRA value indicates an increased possibility that a treatment is in the top rank. A treatment which is certain to be the best will have a SUCRA value of $100 \%$ (i.e. treatment is ranked first in all NMA simulations) and a treatment certain to be the worst will have a value of $0 \%$ (i.e. treatment is ranked last in all NMA simulations) [34].

This article does not contain any new studies with human or animal subjects performed by any of the authors.

\section{RESULTS}

\section{Identified Publications}

A PRISMA flow diagram of the SLR is shown in Fig. 1. In total, 52 publications reporting on 18 unique trials were included in the SLR. Of these, 15 trials $[19,30,35-48]$ were considered as potentially relevant for inclusion in the NMA, and 3 [44, 45, 49] were excluded. The rationale for excluding these trials is detailed in the supplementary material (Table S6). Of these 15 trials, 3 further trials were excluded as not meeting the NMA criteria. Specifically, the GetGoal-Duo2 and Diamant et al. 2014 studies $[38,50]$ were excluded as they reported results for relevant interventions with only secondary comparators. The insulin glargine treatment arm of the AWARD-4 study [30] was also removed for similar reasons. Furthermore, the LIRA ADD2INSULIN Japan study [46] was excluded as it was conducted in a Japanese-only population and reported data at 36 weeks, whereas other included trials reported data at 24-30 weeks.

Overall, the heterogeneity analysis (see supplementary material) indicated the study design and patient characteristics across the 12 included trials [19, 30, 35-37, 39, 41-43, 47, 48, 51] were sufficiently aligned with the PIONEER 8 trial and generalisable to the population of interest to be combined in the analyses. Namely, the mean age of patients varied between 55.0 and 73.0 years, the mean body weight ranged between 66.0 and $94.0 \mathrm{~kg}, \mathrm{HbA}_{1} \mathrm{C}$ levels between 7.6 and $8.5 \%$, the duration of diabetes was 9.0-16.8 years, and background therapy was insulin with or without metformin (Table S7).

However, five trials $[30,37,42,47,48]$ in the base case network were considered as potential outliers (i.e. differed significantly from other trials to be considered in the statistical analysis) and were consequently excluded. The GetGoal-O trial was conducted exclusively in elderly subjects [37], and the GetGoal-L-C and GetGoal-L-Asia trials were conducted primarily in an Asian population [47, 48]. The GetGoalDuo 1 trial included subjects who were newly initiated on basal insulin and only included if they were uncontrolled after 12 weeks [42]. Finally, the AWARD-4 trial included subjects who received mixed insulins [30].

In total, seven trials $[19,35,36,39$, $41,43,51]$ were considered in the NMA and formed a connected network (Fig. 2) comparing once-daily oral semaglutide (7 and $14 \mathrm{mg}$ doses) with once-weekly dulaglutide $1.5 \mathrm{mg}$, onceweekly exenatide $2 \mathrm{mg}$, twice-daily exenatide $10 \mu \mathrm{g}$, once-daily liraglutide $1.8 \mathrm{mg}$, once-daily lixisenatide $20 \mu \mathrm{g}$ and once-weekly injectable semaglutide ( 0.5 and $1.0 \mathrm{mg}$ doses). All seven trials reported on at least one outcome of interest at 24-30 weeks' follow-up (Tables S8-S12). Therefore, it was decided to analyse each efficacy outcome assessed at the 6 -month ( $26 \pm 4$ weeks) follow-up. Overall, the level of response to treatment within the $26 \pm 4$ week target range was deemed unlikely 
Systematic literature review, 1 January 1994 to 9 July 2019

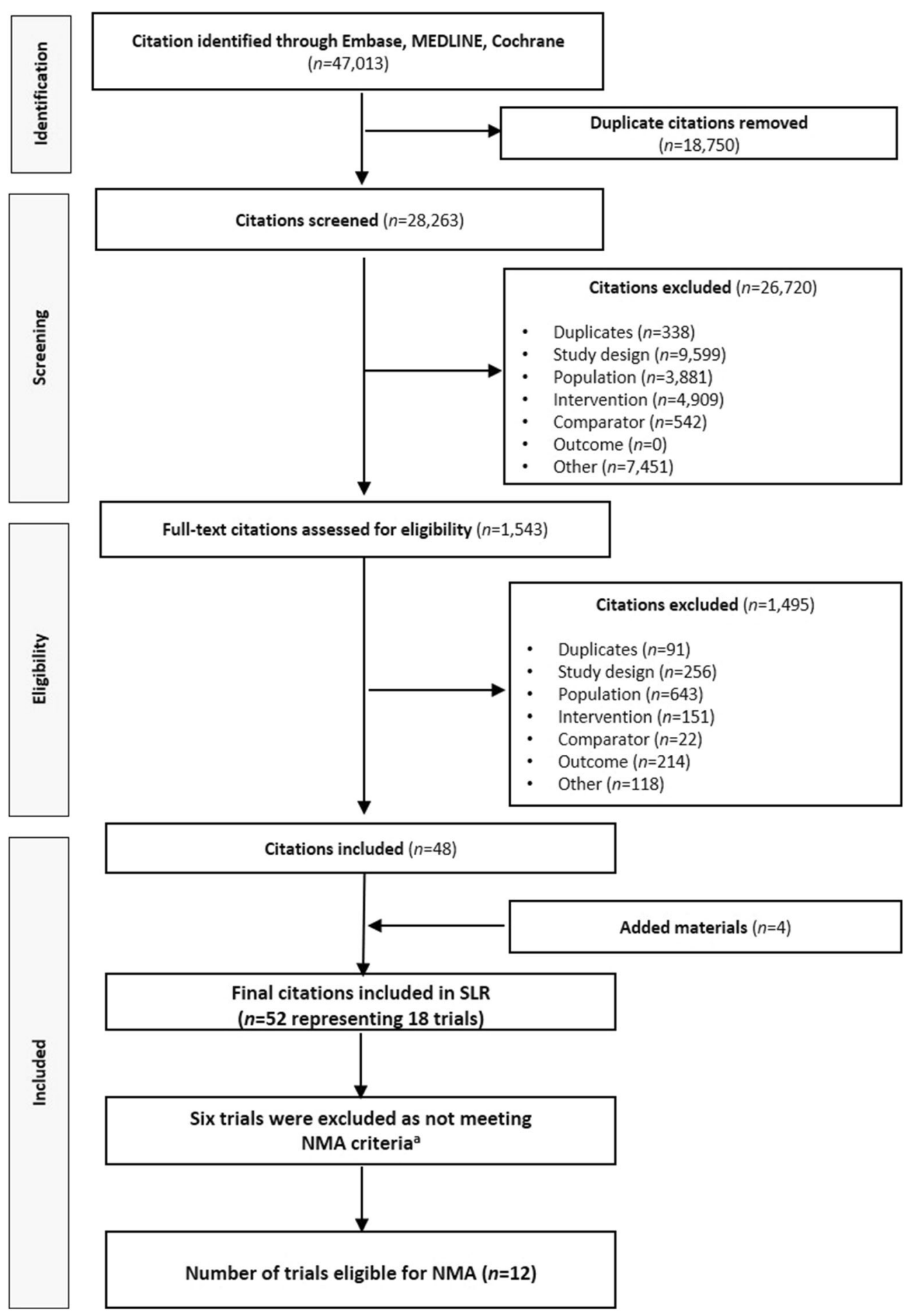

Fig. 1 PRISMA flow diagram of the SLR. NMA network meta-analysis, PRISMA Preferred Reporting Items for Systematic Reviews and Meta-Analyses, SLR systematic literature review. ${ }^{a}$ The rationale for excluding the six trials is detailed in Table S37 


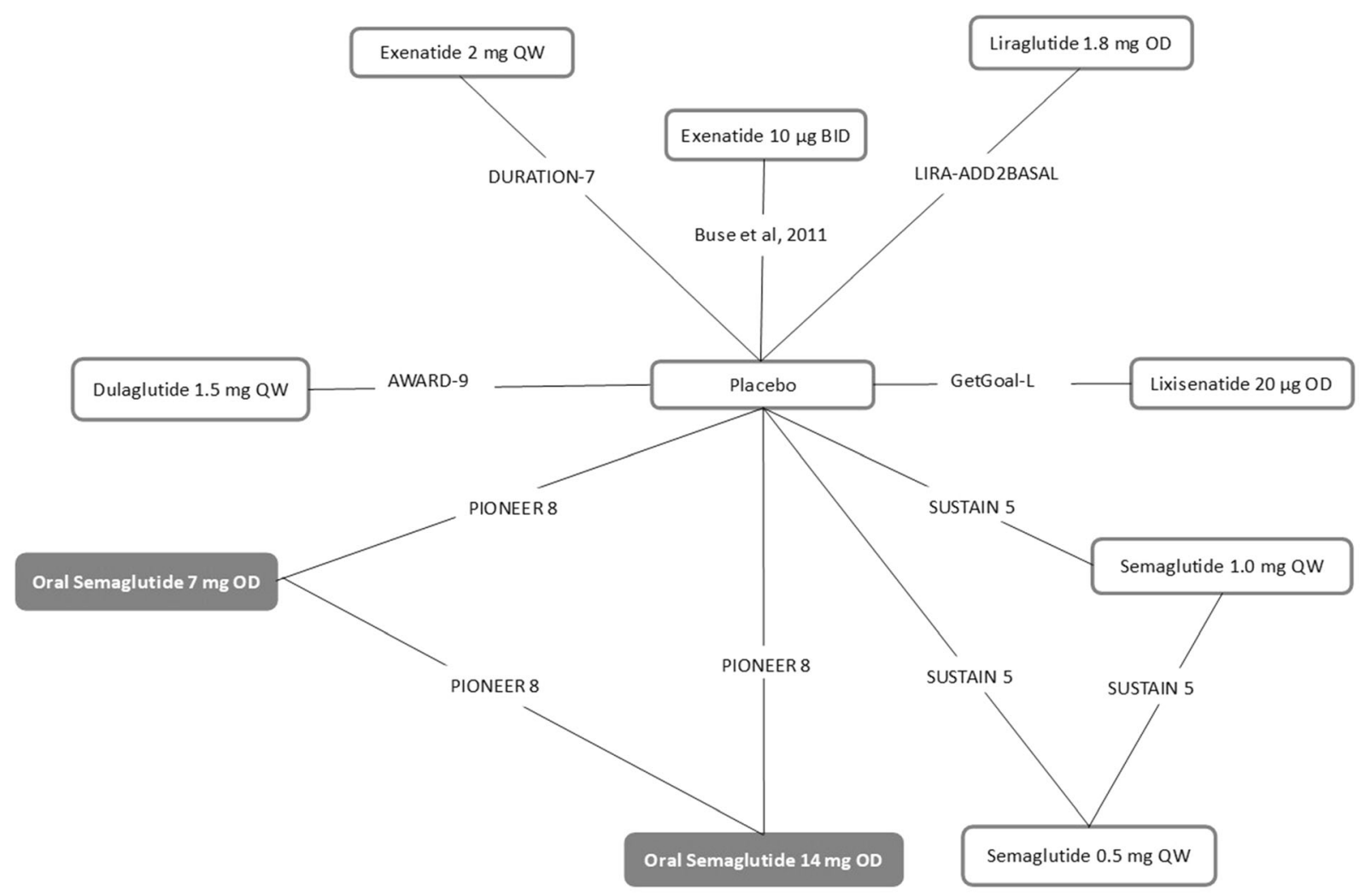

Fig. 2 Base case evidence network for six outcomes ${ }^{\mathrm{a}}$ (seven studies). BID twice daily, $O D$ once daily, $Q W$ once weekly. autcomes included: change from baseline in $\mathrm{HbA}_{1 \mathrm{c}}$ and body weight, proportion of subjects achieving $\mathrm{HbA}_{1 \mathrm{c}}<7 \%$,

to vary considerably; 8 of the 12 trials reported data at either 24 or 26 weeks.

The quality assessment (Fig. S1) indicated that the highest risk of bias across the studies was associated with elements of study blinding and reporting. Additionally, the risk of bias was considered low or unclear across the studies for the remaining elements of bias assessment.

\section{Network Meta-analysis Results}

Seven trials were included in the analyses; the overall evidence network is shown in Fig. 2. The evidence networks for the proportion of subjects achieving $\mathrm{HbA}_{1 \mathrm{c}} \leq 6.5 \%$ and the proportion of subjects achieving the composite endpoint and SBP are available in the supplementary material (Figs. S2-S4). Base case results of the NMA for once-daily oral semaglutide incidence of nausea, vomiting and diarrhoea. Base case networks for systolic blood pressure, proportion of subjects achieving $\mathrm{HbA}_{\mathrm{lc}}<6.5 \%$ and composite endpoint are presented in Fig. S2-S4

$14 \mathrm{mg}$ are presented in Fig. 3 for efficacy outcomes and in Fig. 4 for safety outcomes. The full matrices of relative treatment effect results are presented in the supplementary material (Tables S13-S21). The SUCRA and median ranks for each outcome are presented in the supplementary material (Tables S22 and S23). Results for the once-daily oral semaglutide $7 \mathrm{mg}$ dose are available in the supplementary material (Table S24). Additionally, the estimated absolute treatment effects for each outcome are available in the supplementary material (Table S25).

\section{Glycaemic Control}

Change from Baseline in $\mathrm{HbA}_{1 \mathrm{c}}$

All seven studies reported data on the change in $\mathrm{HbA}_{1 \mathrm{c}}$ from baseline at $26 \pm 4$ weeks (Table S8). 
a

Oral semaglutide $14 \mathrm{mg} O D$ vs comparator

Treatment difference: $\mathrm{HbA}_{1 \mu} \%$ (95\% Crl)

Treatment

Dulaglutide $1.5 \mathrm{mg} \mathrm{QW}$

Exenatide $10 \mu \mathrm{g}$ BID

Exenatide $2.0 \mathrm{mg} \mathrm{QW}$

Liraglutide $1.8 \mathrm{mg} O D$

Lixisenatide $20 \mu \mathrm{g} O D$

Placebo

Semaglutide $0.5 \mathrm{mg} \mathrm{QW}$

Semaglutide $1.0 \mathrm{mg}$ QW

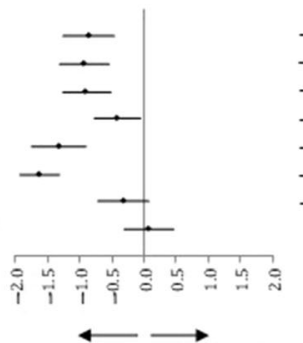

Favours oral semaglutide $14 \stackrel{\mathrm{mg} O D}{\mathrm{OD}} \overrightarrow{\text { Favours comparator }}$

$$
\begin{array}{ll}
-0.85 & (-1.25,-0.45) \\
-0.93 & (-1.32,-0.54) \\
-0.89 & (-1.27,-0.51) \\
-0.42 & (-0.78,-0.05) \\
-1.32 & (-1.74,-0.91) \\
-1.62 & (-1.93,-1.31) \\
-0.32 & (-0.72,0.08) \\
0.08 & (-0.32,0.47)
\end{array}
$$

C

Oral semaglutide $14 \mathrm{mg} O D$ vs comparator $\mathrm{HbA}_{1 \mathrm{~s}}<6.5 \%$ : Odds ratio ( $95 \% \mathrm{Crl}$ )

Treatment

Dulaglutide $1.5 \mathrm{mg} \mathrm{QW}$

Exenatide $10 \mu \mathrm{g}$ BID

Liraglutide $1.8 \mathrm{mg} O D$

Lixisenatide $20 \mu \mathrm{g} O D$

Placebo

Semaglutide $0.5 \mathrm{mg} \mathrm{QW}$

Semaglutide $1.0 \mathrm{mg}$ QW

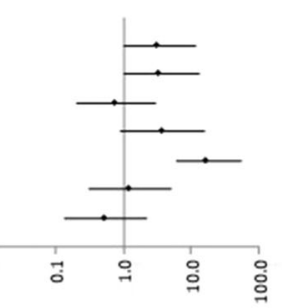

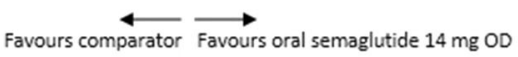

$3.28(1.05,11.81)$

$3.43(1.05,12.99)$

$0.76(0.21,3.02)$

$3.84(0.94,15.91)$

$16.64(6.17,54.01)$

$1.26(0.32,5.12)$

$0.55(0.14,2.23)$

Oral semaglutide $14 \mathrm{mg}$ OD vs comparator

e Treatment
Dulaglutide $1.5 \mathrm{mg} \mathrm{QW}$
Exenatide $2.0 \mathrm{mg} \mathrm{QW}$
Liraglutide $1.8 \mathrm{mg} \mathrm{OD}$
Placebo
Semaglutide $0.5 \mathrm{mg} \mathrm{QW}$ Semaglutide $0.5 \mathrm{mg} \mathrm{QW}$
Semaglutide $1.0 \mathrm{mg} \mathrm{QW}$

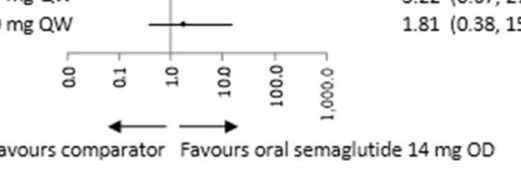

Fig. 3 Forest plots of the NMA results-once-daily oral semaglutide $14 \mathrm{mg}$ vs. comparator for efficacy outcomes. $B I D$ twice-daily, $C r I$ credible interval, $H b A_{1 c}$ glycated haemoglobin, $N M A$ network meta-analysis, $O D$ oncedaily, $Q W$ once-weekly, $S B P$ systolic blood pressure. Treatment differences are considered significant when the $95 \% \mathrm{CrI}$ excludes the null value. Odds ratios are considered significant when the $95 \% \mathrm{CrI}$ excludes 1 . The

Once-daily oral semaglutide $14 \mathrm{mg}$ was associated with a significantly greater reduction in $\mathrm{HbA}_{1 \mathrm{c}}$ vs. once-weekly dulaglutide $1.5 \mathrm{mg}$, twice-daily exenatide $10 \mu \mathrm{g}$, once-weekly exenatide $2 \mathrm{mg}$, once-daily liraglutide $1.8 \mathrm{mg}$ and once-daily lixisenatide $20 \mu \mathrm{g} \quad$ (Fig. 3a and b

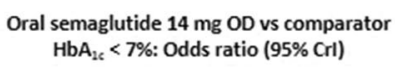

Oral semaglutide $14 \mathrm{mg} O D$ vs comparator $\mathrm{HbA}_{1 \mathrm{c}}<7 \%$ : Odds ratio ( $95 \% \mathrm{Crl}$ )

Treatment

Dulaglutide $1.5 \mathrm{mg} \mathrm{QW}$

Exenatide $10 \mu \mathrm{g}$ BID

Exenatide $2.0 \mathrm{mg} \mathrm{QW}$

Liraglutide $1.8 \mathrm{mg} O D$

Lixisenatide $20 \mu \mathrm{g} O$

Placebo

Semaglutide $0.5 \mathrm{mg} \mathrm{QW}$

Semaglutide $1.0 \mathrm{mg} \mathrm{QW}$

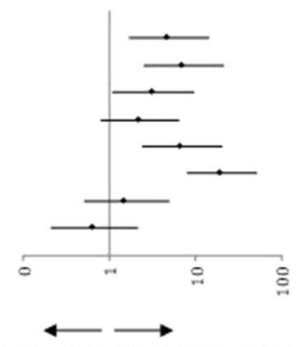

$4.80(1.73,14.14)$

$7.06(2.55,21.44)$

$3.13(1.08,9.79)$

$2.18(0.81,6.46)$

$6.86(2.41,20.78)$

$19.33(8.05,51.58)$

$1.49(0.51,4.84)$

$0.64(0.21,2.13)$

Favours comparator Favours oral semaglutide $14 \mathrm{mg} O D$

d

Oral semaglutide $14 \mathrm{mg}$ OD vs comparator Oral semaglutide $14 \mathrm{mg}$ OD vs comparator
Treatment difference: Weight, $\mathrm{kg}$ (95\% Crl)

Treatment

Dulaglutide $1.5 \mathrm{mg} \mathrm{QW}$

Exenatide $10 \mu \mathrm{g}$ BID

Exenatide $2.0 \mathrm{mg}$ QW

Liraglutide $1.8 \mathrm{mg} O D$

Lixisenatide $20 \mu \mathrm{g} O D$

Placebo

Semaglutide $0.5 \mathrm{mg}$ QW

Semaglutide $1.0 \mathrm{mg}$ QW

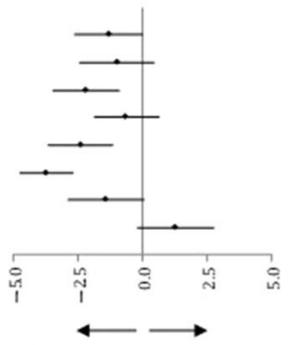

$-1.28(-2.61,0.03)$

$-0.96(-2.41,-0.48)$

$-2.21(-3.45,-0.92)$

$-0.61(-1.87,0.66)$

$-2.39(-3.66,-1.14)$

$-3.71(-4.73,-2.67)$

$-1.41(-2.86,0.05)$

$1.30(-0.17,2.76)$

Favours oral semaglutide $14 \mathrm{mg} O D$ Favours comparator

f

Oral semaglutide $14 \mathrm{mg}$ OD vs comparator

\section{Treatment}

Exenatide $10 \mu \mathrm{g}$ BID

Exenatide $2.0 \mathrm{mg} \mathrm{QW}$

Liraglutide $1.8 \mathrm{mg} O D$

Placebo

Semaglutide $0.5 \mathrm{mg} \mathrm{QW}$

Semaglutide $1.0 \mathrm{mg}$ QW

Treatment difference: SBP $(95 \% \mathrm{Crl})$

$$
\text { Favours oral semaglutide } 14 \mathrm{mg} \text { OD }
$$

$1.74(-3.39,6.87)$

$-0.75(-5.43,3.89)$

$2.36(-2.14,7.02)$

$-2.66(-6.57,1.27)$

$0.62(-4.63,5.99)$

$3.66(-1.57,8.98)$

NMA results are presented as forest plots for: a change from baseline in $\mathrm{HbA}_{1 \mathrm{c}}$; $\mathbf{b}$ proportion of subjects achieving target $\mathrm{HbA}_{1 \mathrm{c}}<7 \%$; c $\mathrm{HbA}_{1 \mathrm{c}} \leq 6.5 \%$; d change from baseline in body weight; e proportion of subjects achieving composite endpoint; $\mathbf{f}$ change from baseline in SBP. $X$-axis is presented as a logarithmic scale for graphs displaying odds ratio data

Table S13). Reductions in $\mathrm{HbA}_{1 \mathrm{c}}$ for once-daily oral semaglutide $14 \mathrm{mg}$ were numerically greater, although not statistically significant, vs. once-weekly injectable semaglutide $0.5 \mathrm{mg}$. Once-weekly injectable semaglutide $1 \mathrm{mg}$ was associated with numerically greater, but not 


\section{a}

Treatment

Dulaglutide $1.5 \mathrm{mg} \mathrm{QW}$

Exenatide $10 \mu \mathrm{g}$ BID

Exenatide $2.0 \mathrm{mg} \mathrm{QW}$

Liraglutide $1.8 \mathrm{mg} O D$

Lixisenatide $20 \mu \mathrm{g} O D$

Placebo

Semaglutide $0.5 \mathrm{mg} \mathrm{QW}$

Semaglutide $1.0 \mathrm{mg} \mathrm{QW}$

Oral semaglutide $14 \mathrm{mg}$ OD vs comparator

Nausea: Odds ratio (95\% Crl)

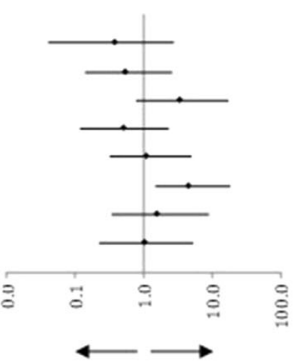

$0.39(0.04,2.71)$

$0.57(0.14,2.62)$

$3.41(0.81,16.64)$

$0.51(0.12,2.31)$

$1.15(0.32,4.94)$

$4.56(1.52,17.91)$

$1.64(0.35,8.81)$

$1.03(0.23,5.25)$

Favours oral semaglutide $14 \mathrm{mg}$ OD Favours comparator

b
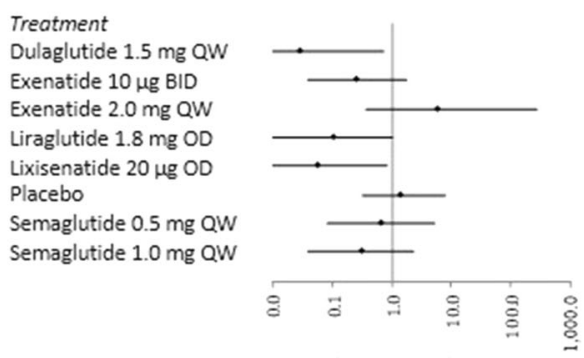

$\longleftarrow \longrightarrow$

Favours oral semaglutide $14 \mathrm{mg} O D$ Favours comparator

C

Oral semaglutide $14 \mathrm{mg}$ OD vs comparator

Diarrhoea: Odds ratio ( $95 \% \mathrm{Crl}$ )

Treatment

Dulaglutide $1.5 \mathrm{mg} \mathrm{QW}$

Exenatide $10 \mu \mathrm{g} \mathrm{BID}$

Exenatide $2.0 \mathrm{mg} \mathrm{QW}$

Liraglutide $1.8 \mathrm{mg} O D$

Lixisenatide $20 \mu \mathrm{g} O D$

Placebo

Semaglutide $0.5 \mathrm{mg} \mathrm{QW}$

Semaglutide $1.0 \mathrm{mg} \mathrm{QW}$

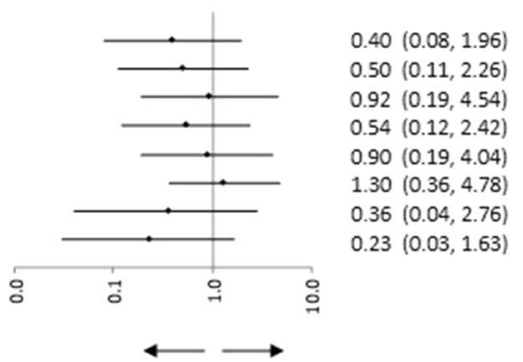

$0.03(0.01,0.73)$

$0.26(0.04,1.77)$

$5.92(0.36,264.01)$

$0.11(0.01,1.01)$

$0.06(0.01,0.82)$

$1.44(0.31,7.74)$

$0.66(0.08,5.11)$

$0.32(0.04,2.34)$ 
Proportion of Subjects Achieving $\mathrm{HbA}_{1 c}<7 \%$ or $\leq 6.5 \%$

Data on the proportion of subjects achieving $\mathrm{HbA}_{1 \mathrm{c}}<7 \%$ or $\leq 6.5 \%$ at $26 \pm 4$ weeks were reported in seven and six studies, respectively (Table S9). Once-daily oral semaglutide $14 \mathrm{mg}$ was associated with significantly higher odds of achieving $\quad \mathrm{HbA}_{1 \mathrm{c}}<7 \%$ vs. once-weekly dulaglutide $1.5 \mathrm{mg}$, twice-daily exenatide $10 \mu \mathrm{g}$, once-weekly exenatide $2 \mathrm{mg}$ and once-daily lixisenatide $20 \mu \mathrm{g}$ (Fig. $3 \mathrm{~b}$ and Table S14). The odds of achieving $\mathrm{HbA}_{1 \mathrm{c}}<7 \%$ with once-daily oral semaglutide $14 \mathrm{mg}$ were numerically higher, although not statistically significant, vs. once-daily liraglutide $1.8 \mathrm{mg}$ and once-weekly injectable semaglutide $0.5 \mathrm{mg}$. Once-weekly injectable semaglutide $1 \mathrm{mg}$ was associated with numerically higher, although not statistically significant, odds of achieving $\mathrm{HbA}_{1 \mathrm{c}}<7 \%$ vs. once-daily oral semaglutide $14 \mathrm{mg}$.

Once-daily oral semaglutide $14 \mathrm{mg}$ was also associated with significantly higher odds of achieving $\quad \mathrm{HbA}_{1 \mathrm{c}} \leq 6.5 \%$ vs. once-weekly dulaglutide $1.5 \mathrm{mg}$ and twice-daily exenatide $10 \mu \mathrm{g}$ (Fig. 3c and Table S15). The odds of achieving $\mathrm{HbA}_{1 \mathrm{c}} \leq 6.5 \%$ with once-daily oral semaglutide $14 \mathrm{mg}$ were numerically higher, although not statistically significant, vs. oncedaily lixisenatide $20 \mu \mathrm{g}$ and once-weekly injectable semaglutide $0.5 \mathrm{mg}$. Once-weekly injectable semaglutide $1 \mathrm{mg}$ and once-daily liraglutide $1.8 \mathrm{mg}$ were associated with numerically higher odds of achieving $\mathrm{HbA}_{1 \mathrm{c}} \leq 6.5 \%$ vs. once-daily oral semaglutide $14 \mathrm{mg}$. For both $\mathrm{HbA}_{1 \mathrm{c}}$ target outcomes, once-daily oral semaglutide $14 \mathrm{mg}$ achieved median rankings of second and third and SUCRA values of $87.6 \%$ and $76.0 \%$, respectively (Tables S22 and S23), indicating that this treatment is among the best within this network.

\section{Body Weight}

All seven studies reported data on the change from baseline in body weight at $26 \pm 4$ weeks (Table S10). Once-daily oral semaglutide $14 \mathrm{mg}$ was associated with a significantly greater reduction in weight vs. once-weekly exenatide $2 \mathrm{mg}$ and once-daily lixisenatide $20 \mu \mathrm{g}$ (Fig. 3d and Table S16). Reductions in weight with oncedaily oral semaglutide $14 \mathrm{mg}$ were numerically greater, although not statistically significant, vs. all other comparators, except for once-weekly injectable semaglutide $1 \mathrm{mg}$, which was associated with a numerically greater, although not statistically significant, reduction in body weight vs. once-daily oral semaglutide $14 \mathrm{mg}$. Once-daily oral semaglutide $14 \mathrm{mg}$ had a median rank of second and a SUCRA value of $85.4 \%$ (Tables S22 and S23), indicating that this treatment is among the best within this network.

\section{Proportion of Subjects Achieving the Composite Endpoint}

Five studies reported data on the proportion of subjects achieving the composite endpoint, defined as $\mathrm{HbA}_{1 \mathrm{c}}<7 \%$ without weight gain and hypoglycaemia at $26 \pm 4$ weeks (Table S9). Once-daily oral semaglutide $14 \mathrm{mg}$ was associated with significantly higher odds of achieving the composite endpoint vs. once-weekly dulaglutide $1.5 \mathrm{mg}$ and once-daily liraglutide $1.8 \mathrm{mg}$ (Fig. 3e and Table S17). The odds of achieving the composite endpoint with oncedaily oral semaglutide $14 \mathrm{mg}$ were numerically higher, but not statistically significant, vs. $0.5 \mathrm{mg}$ and $1 \mathrm{mg}$ doses of once-weekly injectable semaglutide. Once-daily oral semaglutide $14 \mathrm{mg}$ had a median rank of first and a SUCRA value of $95.0 \%$ (Tables S22 and S23), indicating that this treatment is likely to be the best in this network.

\section{Systolic Blood Pressure}

Five studies reported data on the change from baseline in SBP at $26 \pm 4$ weeks (Table S11). The change in SBP with once-daily oral semaglutide $14 \mathrm{mg}$ was not significantly different from those observed with the injectable GLP-1 RA comparators (Fig. 3F and Table S18).

\section{Incidence of Nausea, Vomiting and Diarrhoea}

All seven studies reported data on the incidence of nausea, vomiting and diarrhoea at 
$26 \pm 4$ weeks (Table S12). Once-daily oral semaglutide $14 \mathrm{mg}$ was not associated with significantly different odds of experiencing nausea or diarrhoea vs. GLP-1 RA comparators. The odds of vomiting with once-daily oral semaglutide $14 \mathrm{mg}$ were significantly lower vs. once-weekly dulaglutide $1.5 \mathrm{mg}$ and once-daily lixisenatide $20 \mu \mathrm{g}$ (Fig. 4 and Tables S19-S21).

\section{DISCUSSION}

The aim of this study was to assess the relative efficacy and safety of once-daily oral semaglutide (7 and $14 \mathrm{mg})$ compared with injectable GLP-1 RAs as an add-on to insulin therapy in people with T2D inadequately controlled on basal insulin.

The analyses indicated that once-daily oral semaglutide $14 \mathrm{mg}$ was associated with a significantly greater reduction in $\mathrm{HbA}_{1 \mathrm{c}}$ at $26 \pm 4$ weeks vs. most injectable GLP-1 RA comparators; differences vs. once-weekly injectable semaglutide $(0.5 \mathrm{mg}$ and $1 \mathrm{mg}$ doses $)$ were not statistically significant. Once-daily oral semaglutide $14 \mathrm{mg}$ was also associated with significantly greater reductions in body weight vs. once-weekly exenatide $2 \mathrm{mg}$ and once-daily lixisenatide $20 \mu \mathrm{g}$; non-statistically significant weight reductions in favour of once-daily oral semaglutide $14 \mathrm{mg}$ were observed vs. all other comparators except once-weekly injectable semaglutide $1 \mathrm{mg}$. Similar results were observed for the proportion of people achieving glycaemic treatment targets at $26 \pm 4$ weeks. These findings are supported by treatment ranks and SUCRA values, indicating that once-daily oral semaglutide $14 \mathrm{mg}$ is the second-best treatment, after once-weekly injectable semaglutide $1 \mathrm{mg}$, for reducing $\mathrm{HbA}_{1 \mathrm{c}}$ levels and body weight at $26 \pm 4$ weeks. Based on treatment ranks and SUCRA values, oncedaily oral semaglutide $14 \mathrm{mg}$ is likely to be among the best treatments in the evidence network for achieving $\mathrm{HbA}_{1 \mathrm{c}}<7 \%$ without weight gain and hypoglycaemia (i.e. the composite outcome).

Balance between efficacy improvements and associated risk of adverse events is warranted for effective treatment. In this study, increased efficacy was achieved without an increase in adverse events. Once-daily oral semaglutide $14 \mathrm{mg}$ was associated with a significantly lower probability of vomiting compared with onceweekly dulaglutide $1.5 \mathrm{mg}$ and once-daily lixisenatide $20 \mu \mathrm{g}$. Similar odds of experiencing nausea and diarrhoea were observed when compared with all other GLP-1 RA comparators.

To our knowledge, this is the first NMA comparing the relative efficacy and safety of oncedaily oral semaglutide vs. injectable GLP-1 RAs as an add-on to insulin therapy in people with T2D inadequately controlled on basal insulin. A recently published NMA by Nuhoho et al. compared the relative efficacy and safety of once-daily oral semaglutide $14 \mathrm{mg}$ vs. injectable GLP-1 RAs in people with T2D inadequately controlled on 1-2 oral anti-diabetic drugs [52]. While the target population in this NMA is different from the one considered by Nuhoho et al., findings in terms of GLP-1 RAs' relative efficacy and ranking are consistent between the two studies, indicating that once-daily oral semaglutide is an efficacious addon therapy for a broad population with T2D, including people with advanced disease.

Findings from this NMA are robust, based on the quality and homogeneity of the trials included in the network, and the alignment of the methodology with guidelines from NICE, ISPOR and the Cochrane Institute [21, 23-26]. Furthermore, all randomised controlled trials included in the NMA were identified in an SLR to ensure that all available evidence was considered.

This NMA was subject to some limitations. There were some differences in the time points reported in the individual studies, which were addressed by using the well-accepted method of applying a time point window (26 \pm 4 weeks) into the analyses [53-55]. Differences in the insulin titration rules were also observed across the studies, with various insulin algorithms being used such as treat-to-target, Initiate Insulin by Aggressive Titration and Education, titration at the investigators' discretion, or capping of basal insulin dose at a level equal to the pre-study level. Consequently, there may be variability in the placebo effect observed in different studies, which may impact treatment outcomes. The relatively small sample size of 
the once-daily oral semaglutide arms in the network compared with the injectable GLP-1 RAs arms may also be a limitation of the NMA. Furthermore, as it was not possible to conduct a random-effects analysis, the fixed-effects model was chosen for the base case analyses; this approach does not allow an estimate of heterogeneity between studies and may represent a limitation to this NMA given that heterogeneity within the data sets of each analysis is inevitable. Also, as there was only one study linking each treatment in the evidence network, there was no opportunity to assess for inconsistency in the NMA. Finally, while bias was considered low across the studies, inherent publication bias as well as time lag and language bias were assumed, as with any analysis based on published data [56]. While these differences made the comparisons between included trials challenging, such limitation is common in all NMAs; thus, caution is advised when interpreting NMA results.

\section{CONCLUSION}

Once-daily oral semaglutide $14 \mathrm{mg}$ as an add-on to basal insulin is an efficacious treatment for reducing $\mathrm{HbA}_{1 \mathrm{c}}$ and body weight and increasing the proportion of people with T2D meeting glycaemic treatment targets at $26 \pm 4$ weeks. Based on the safety outcomes assessed, oncedaily oral semaglutide $14 \mathrm{mg}$ has a similar tolerability profile to injectable GLP-1 RAs in this population. In addition, once-daily oral semaglutide offers people with T2D the option of an oral treatment which may reduce the injection burden in a population requiring GLP-1 RAs.

\section{ACKNOWLEDGEMENTS}

Funding. This study and the journal's Rapid Service fee were funded by Novo Nordisk.

Editorial and Other Assistance. Editorial assistance in the preparation of this manuscript was provided by Sonia Alesso of DRG Abacus
Part of Clarivate. This was funded by Novo Nordisk.

Authorship. The SLR and feasibility assessment were conducted by Palvi Gupta of DRG Abacus Part of Clarivate and Jatin Gupta of CONTINUUM India Ltd. The NMA was conducted by Michelle Orme of ICERA Consulting Ltd. All named authors meet the International Committee of Medical Journal Editors (ICMJE) uniform requirements for authorship for this manuscript, take responsibility for the integrity of the work, and have given final approval for the version to be published. All authors had full access to all the data in this study and take complete responsibility for the integrity and accuracy of the data analysis.

Disclosures. Barrie Chubb is an employee and stakeholder of Novo Nordisk. Palvi Gupta is an employee of DRG Abacus Part of Clarivate. Jatin Gupta was an employee of DRG Abacus Part of Clarivate at the time the NMA and manuscript were developed and is currently an employee of CONTINUUM India Limited. Solomon Nuhoho was an employee of Novo Nordisk at the time the NMA and manuscript were developed. Klaus Kallenbach is an employee of Novo Nordisk. Michelle Orme is an outcomes research consultant with ICERA Consulting Ltd.

Compliance with Ethics Guidelines. This article is based on previously conducted studies and does not contain any studies with human participants or animals performed by any of the authors.

Data availability. All data generated or analysed during this study are included in this published article as supplementary information files.

Open Access. This article is licensed under a Creative Commons Attribution-NonCommercial 4.0 International License, which permits any non-commercial use, sharing, adaptation, distribution and reproduction in any medium or format, as long as you give appropriate credit to the original author(s) and the source, provide 
a link to the Creative Commons licence, and indicate if changes were made. The images or other third party material in this article are included in the article's Creative Commons licence, unless indicated otherwise in a credit line to the material. If material is not included in the article's Creative Commons licence and your intended use is not permitted by statutory regulation or exceeds the permitted use, you will need to obtain permission directly from the copyright holder. To view a copy of this licence, visit http://creativecommons.org/licenses/by$\mathrm{nc} / 4.0 /$.

\section{REFERENCES}

1. Forbes JM, Cooper ME. Mechanisms of diabetic complications. Physiol Rev. 2013;93(1):137-88.

2. Caro JJ, Ward AJ, O'Brien JA. Lifetime costs of complications resulting from type 2 diabetes in the US. Diabetes Care. 2002;25(3):476-81.

3. Hex N, Bartlett C, Wright D, Taylor M, Varley D. Estimating the current and future costs of type 1 and type 2 diabetes in the UK, including direct health costs and indirect societal and productivity costs. Diabet Med. 2012;29(7):855-62.

4. Moore DJ, Gregory JM, Kumah-Crystal YA, Simmons JH. Mitigating micro-and macro-vascular complications of diabetes beginning in adolescence. Vasc Health Risk Manag. 2009;5:1015-31.

5. Davies MJ, D'Alessio DA, Fradkin J, et al. Management of hyperglycemia in type 2 diabetes, 2018. A consensus report by the American Diabetes Association (ADA) and the European Association for the Study of Diabetes (EASD). Diabetes Care. 2018: dci180033.

6. International Diabetes Federation (IDF). Clinical practice recommendations for managing type 2 diabetes in primary care, 2017. https://www.idf.org/ e-library/guidelines/128-idf-clinical-practicerecommendations-for-managing-type-2-diabetesin-primary-care.html. Accessed 3 Mar 2021.

7. American Diabetes Association. Introduction: standards of medical care in diabetes-2020. Diabetes Care. 2020;43(Suppl 1):S1-S2.

8. American Association of Clinical Endocrinologists $\&$ American College of Endocrinology (AACE/ACE). Comprehensive type 2 diabetes management algorithm 2019. https://pro.aace.com/disease-stateresources/diabetes/clinical-practice-guidelinestreatment-algorithms/comprehensive. Accessed 3 Mar 2021.

9. Handelsman Y, Bloomgarden ZT, Grunberger G, et al. American Association of Clinical Endocrinologists and American College of Endocrinologyclinical practice guidelines for developing a diabetes mellitus comprehensive care plan. Endocr Pract. 2015;21(Suppl 1):1-87.

10. American Diabetes Association. Pharmacologic approaches to glycemic treatment: Standards of Medical Care in Diabetes-2021. Diabetes Care. 2021;44(Suppl 1):S111-24.

11. Garber AJ, Abrahamson MJ, Barzilay JI, et al. Consensus statement by the American Association of Clinical Endocrinologists and American College of Endocrinology on the comprehensive type 2 diabetes management algorithm-2019 executive summary. Endocr Pract. 2019;25(1):69-100.

12. Mauricio D, Meneghini L, Seufert J, et al. Glycaemic control and hypoglycaemia burden in patients with type 2 diabetes initiating basal insulin in Europe and the USA. Diabetes Obes Metab. 2017;19(8): 1155-64.

13. Eng C, Kramer CK, Zinman B, Retnakaran R. Glucagon-like peptide-1 receptor agonist and basal insulin combination treatment for the management of type 2 diabetes: a systematic review and meta-analysis. Lancet. 2014;384(9961):2228-34.

14. Giorgino F, Bonadonna RC, Gentile S, Vettor R, Pozzilli P. Treatment intensification in patients with inadequate glycemic control on basal insulin: rationale and clinical evidence for the use of shortacting and other glucagon-like peptide- 1 receptor agonists. Diabetes Metab Res Rev. 2016;32(6): 497-511.

15. Pieber TR, Bode B, Mertens A, et al. Efficacy and safety of oral semaglutide with flexible dose adjustment versus sitagliptin in type 2 diabetes (PIONEER 7): a multicentre, open-label, randomised, phase $3 \mathrm{a}$ trial. Lancet Diabetes Endocrinol. 2019;7(7):528-39.

16. Pratley R, Amod A, Hoff ST, et al. Oral semaglutide versus subcutaneous liraglutide and placebo in type 2 diabetes (PIONEER 4): a randomised, doubleblind, phase 3a trial. Lancet. 2019;394(10192): 39-50.

17. Rodbard HW, Rosenstock J, Canani LH, et al. Oral semaglutide versus empagliflozin in patients with type 2 diabetes uncontrolled on metformin: the PIONEER 2 trial. Diabetes Care. 2019;42(12): 2272-81. 
18. Rosenstock J, Allison D, Birkenfeld AL, et al. Effect of additional oral semaglutide vs sitagliptin on glycated hemoglobin in adults with type 2 diabetes uncontrolled with metformin alone or with sulfonylurea: the PIONEER 3 randomized clinical trial. J Am Med Assoc. 2019;321(15):1466-80.

19. Zinman B, Aroda VR, Buse JB, et al. Efficacy, safety, and tolerability of oral semaglutide versus placebo added to insulin with or without metformin in patients with type 2 diabetes: the PIONEER 8 trial. Diabetes Care. 2019;42(12):2262-71.

20. Centre for Reviews and Dissemination. Systematic Reviews. 2009. https://www.york.ac.uk/media/crd/ Systematic_Reviews.pdf. Accessed 3 Mar 2021.

21. Higgins JPT, Green S. Cochrane handbook for systematic reviews of interventions version 5.0.2 [updated September 2009]. https://training.cochrane. org/cochrane-handbook-systematic-reviewsinterventions. Accessed 3 Mar 2021.

22. Higgins J, Green S. Cochrane Handbook for Systematic Reviews of Interventions, vol. 5.0.1. https:// training.cochrane.org/cochrane-handbooksystematic-reviews-interventions. Accessed 3 Mar 2021.

23. Dias S, Welton N, Sutton A, Ades A. NICE DSU technical support document 2: a generalised linear modelling framework for pairwise and network meta-analysis of randomised controlled trials. 2011. https://www.ncbi.nlm.nih.gov/books/NBK310366/. Accessed 3 Mar 2021.

24. Dias S, Welton N, Sutton A, Caldwell D, Lu G, Ades A. NICE DSU technical support document 4: inconsistency in networks of evidence based on randomised controlled trials. 2011; last updated April 2014. http://nicedsu.org.uk/wp-content/ uploads/2016/03/TSD4-Inconsistency.final_. 15April2014.pdf. Accessed 3 Mar 2021.

25. Dias S, Welton N, Sutton A, Valdwell D, Guobing L, Ades A. NICE DSU technical support document 3. Heterogeneity: subgroups, meta-regression, bias and bias-adjustment. 2011. https://www.ncbi.nlm. nih.gov/books/NBK395886/pdf/Bookshelf_ NBK395886.pdf. Accessed 3 Mar 2021.

26. Hoaglin DC, Hawkins N, Jansen JP, et al. Conducting indirect-treatment-comparison and network-meta-analysis studies: report of the ISPOR Task Force on indirect treatment comparisons good research practices: part 2. Value Health. 2011;14(4): 429-37.

27. European Medicines Agency. Albiglutide withdrawal. 2018. https://www.ema.europa.eu/en/ documents/assessment-report/public-statement- eperzan-withdrawal-marketing-authorisationeuropean-union_en.pdf. Accessed 3 Mar 2021.

28. Aroda VR, Saugstrup T, Buse JB, Donsmark M, Zacho J, Davies MJ. Incorporating and interpreting regulatory guidance on estimands in diabetes clinical trials: the PIONEER 1 randomized clinical trial as an example. Diabetes Obes Metab. 2019;21(10): 2203-10.

29. Einarson TR, Garg M, Kaur V, Hemels ME. Composite endpoints in trials of type- 2 diabetes. Diabetes Obes Metab. 2014;16(6):492-9.

30. Blonde L, Jendle J, Gross J, et al. Once-weekly dulaglutide versus bedtime insulin glargine, both in combination with prandial insulin lispro, in patients with type 2 diabetes (AWARD-4): a randomised, open-label, phase 3, non-inferiority study. Lancet. 2015;385(9982):2057-66.

31. Novo Nordisk. Data on file. PIONEER 8. Insulin add-on, version 1.0; 12 February 2019. Efficacy and safety of oral semaglutide versus placebo in subjects with type 2 diabetes mellitus treated with insulin: a 52-week, randomised, double-blind, placebo-controlled trial. 2019.

32. Lunn DJ, Thomas A, Best N, Spiegelhalter D. WinBUGS - a Bayesian modelling framework: concepts, structure, and extensibility. Stat Comput. 2000;10: 325-37.

33. Welton NJ, Sutton AJ, Cooper NJ, Abrams KR, Ades AE. Evidence synthesis for decision making in healthcare. 1st ed. New York: Wiley; 2012. p. 124-6.

34. Salanti G, Ades AE, Ioannidis JP. Graphical methods and numerical summaries for presenting results from multiple-treatment meta-analysis: an overview and tutorial. J Clin Epidemiol. 2011;64(2): 163-71.

35. Ahmann A, Rodbard HW, Rosenstock J, et al. Efficacy and safety of liraglutide versus placebo added to basal insulin analogues (with or without metformin) in patients with type 2 diabetes: a randomized, placebo-controlled trial. Diabetes Obes Metab. 2015;17(11):1056-64.

36. Buse JB, Bergenstal RM, Glass LC, et al. Use of twicedaily exenatide in Basal insulin-treated patients with type 2 diabetes: a randomized, controlled trial. Ann Intern Med. 2011;154(2):103-12.

37. Dailey GE, Dex TA, Roberts M, Liu M, Meneilly GS. Efficacy and safety of lixisenatide as add-on therapy to basal insulin in older adults with type 2 diabetes in the GetGoal-O study. J Diabetes. 2019;11(12): 971-81. 
38. Diamant M, Nauck MA, Shaginian R, et al. Glucagon-like peptide 1 receptor agonist or bolus insulin with optimized basal insulin in type 2 diabetes. Diabetes Care. 2014;37(10):2763-73.

39. Guja C, Frías JP, Somogyi A, et al. Effect of exenatide QW or placebo, both added to titrated insulin glargine, in uncontrolled type 2 diabetes: the DURATION-7 randomized study. Diabetes Obes Metab. 2018;20(7):1602-14.

40. Pozzili P, Norwood P, Jodar E, et al. Improved glyacemic control and weight loss with once weekly dulaglutide versus placebo, both added to titrated daily insulin glargine in type 2 diabetes patients (AWARD-9). Abstract 145. In: Presented at 52nd Annual Meeting of the European Association for the Study of Diabetes. Munich, 16 September 2016.

41. Riddle MC, Aronson R, Home P, et al. Adding oncedaily lixisenatide for type 2 diabetes inadequately controlled by established basal insulin: a 24-week, randomized, placebo-controlled comparison (GetGoal-L). Diabetes Care. 2013;36(9):2489-96.

42. Riddle MC, Forst T, Aronson R, et al. Adding oncedaily lixisenatide for type 2 diabetes inadequately controlled with newly initiated and continuously titrated basal insulin glargine: a 24-week, randomized, placebo-controlled study (GetGoal-Duo 1). Diabetes Care. 2013;36(9):2497-503.

43. Rodbard HW, Lingvay I, Reed J, et al. Semaglutide added to basal insulin in type 2 diabetes (SUSTAIN 5): a randomized, controlled trial. J Clin Endocrinol Metab. 2018;103(6):2291-301.

44. Rosenstock J, Fonseca VA, Gross JL, et al. Advancing basal insulin replacement in type 2 diabetes inadequately controlled with insulin glargine plus oral agents: a comparison of adding albiglutide, a weekly GLP-1 receptor agonist, versus thrice-daily prandial insulin lispro. Diabetes Care. 2014;37(8): 2317-25.

45. Rosenstock J, Nino AJ, Soffer J, et al. Near-normoglycemia, with meaningful discontinuations of prandial insulin, by adding weekly albiglutide (Albi) to uncontrolled basal/bolus insulin-treated type 2 diabetes (T2DM). Diabetes. 2018;67(Supplement 1):1073-P.

46. Seino Y, Kaneko S, Fukuda S, et al. Combination therapy with liraglutide and insulin in Japanese patients with type 2 diabetes: a 36-week, randomized, double-blind, parallel-group trial. J Diabetes Investig. 2016;7(4):565-73.

47. Seino Y, Min KW, Niemoeller E, Takami A. Randomized, double-blind, placebo-controlled trial of the once-daily GLP-1 receptor agonist lixisenatide in Asian patients with type 2 diabetes insufficiently controlled on basal insulin with or without a sulfonylurea (GetGoal-L-Asia). Diabetes Obes Metab. 2012;14(10):910-7.

48. Yang W, Min K, Zhou Z, et al. Efficacy and safety of lixisenatide in a predominantly Asian population with type 2 diabetes insufficiently controlled with basal insulin: the GetGoal-L-C randomized trial. Diabetes Obes Metab. 2018;20(2):335-43.

49. Tuttle KR, Lakshmanan MC, Rayner B, et al. Dulaglutide versus insulin glargine in patients with type 2 diabetes and moderate-to-severe chronic kidney disease (AWARD-7): a multicentre, open-label, randomised trial. Lancet Diabetes Endocrinol. 2018;6(8):605-17.

50. Rosenstock J, Hanefeld M, Gentile S. Advancing basal insulin glargine with prandial lixisenatide QD vs insulin glulisine QD or TID in T2DM: the GetGoal-Duo2 evidence-based trial (NCT01768559). Diabetes. 2015;64:LB27-28.

51. Pozzilli P, Norwood P, Jodar E, et al. Placebo-controlled, randomized trial of the addition of onceweekly glucagon-like peptide-1 receptor agonist dulaglutide to titrated daily insulin glargine in patients with type 2 diabetes (AWARD-9). Diabetes Obes Metab. 2017;19(7):1024-31.

52. Nuhoho S, Gupta J, Hansen BB, Fletcher-Louis M, Dang-Tan T, Paine A. Orally administered semaglutide versus GLP-1 RAs in patients with type 2 diabetes previously receiving 1-2 oral antidiabetics: systematic review and network meta-analysis. Diabetes Ther. 2019;10(6):2183-99.

53. Barnett AH, Orme ME, Fenici P, Townsend R, Wygant G, Roudaut M. Systematic review and network meta-analysis to compare dapagliflozin with other diabetes medications in combination with metformin for adults with type 2 diabetes. Intern Med. 2014;S6:006.

54. Kayaniyil S, Lozano-Ortega G, Bennett HA, et al. A network meta-analysis comparing exenatide once weekly with other GLP-1 receptor agonists for the treatment of type 2 diabetes mellitus. Diabetes Ther. 2016;7(1):27-43.

55. Orme ME, Nguyen H, Lu JY, Thomas SA. Comparative effectiveness of glycemic control in patients with type 2 diabetes treated with GLP-1 receptor agonists: a network meta-analysis of placebo-controlled and active-comparator trials. Diabetes Metab Syndr Obes. 2017;10:111-22.

56. Ahmed I, Sutton AJ, Riley RD. Assessment of publication bias, selection bias, and unavailable data in meta-analyses using individual participant data: a database survey. BMJ. 2012;344:d7762. 